\title{
Effect of Enamel Deproteinization Using Ficin on Shear Bond Strength of Orthodontic Brackets
}

\author{
Hamza Gaaloul ${ }^{1 *}$, Ghassen Kallel ${ }^{1}$, Mahassen Barboura ${ }^{2}$, Salah Mezlini ${ }^{3}$, \\ Leila Chekir-Ghedira ${ }^{2}$, Ines Dallel ${ }^{4}$, Samir Tobji ${ }^{4}$ and Adel Ben Amor ${ }^{5}$ \\ ${ }^{1}$ Resident, Department of Orthodontics, Dental Clinic of Monastir, Tunisia \\ ${ }^{2}$ Unit of Bioactive and Natural Substances and Biotechnology UR17ES49, Faculty of \\ Dental Medicine, University of Monastir, Tunisia \\ ${ }^{3}$ Department of Mechanical Engineering, National School of Engineers of Monastir, \\ Tunisia \\ ${ }^{4}$ Professor, Department of Orthodontics, Dental Clinic of Monastir, Tunisia \\ ${ }^{5}$ Head of Orthodontics Department, Dental Clinic of Monastir, Tunisia \\ *Corresponding Author: Hamza Gaaloul, Resident, Department of Orthodontics, \\ Dental Clinic of Monastir, Tunisia.
}

Received: November 29, 2021

Published: January 25, 2022

(C) All rights are reserved by Hamza Gaaloul., et al.

\begin{abstract}
Objective: To test the effect of ficin as an enamel deproteinizing substance on shear bond strength of orthodontic brackets.

Materials and Methods: Forty-two teeth were used and divided into two groups: a control group (enamel surface was not treated with ficin) and a test group (enamel surface was deproteinized by ficin before etching). After bonding, shear bond strength was measured using a universal mechanical test machine. The two groups were compared using independent-samples Student's t-test $(\mathrm{p}<0.05)$.

Results: The ficin group showed higher shear bond strength, the difference was statistically significant $(p=0.037)$.

Conclusion: A deproteinization step using ficin is recommended to be added to the traditional bonding protocol in order to enhance shear bond strength of orthodontic brackets.
\end{abstract}

Keywords: Deproteinization; Ficin; Orthodontic Brackets; Shear Bond Strength

\section{Introduction}

Bonding is the first step of orthodontic treatment whether it is conventional (brackets and tubes' bonding) or with aligners (attachments' bonding). It can directly affect the efficiency and the duration of the treatment [1-4]. Indeed, an increasing of treatment time by 0.6 month for each failed bracket was reported [5] which can cause root resorption [6] and periodontal problems due to the reduction of patient compliance [2,3]. Thus, in order to improve the adhesion between brackets and enamel, many tips were pro- posed such as preparing the tooth surface with air abrasion [7] or Er:YAG lasers [8] and the use of different orthodontic bonding systems $[9,10]$. However, previous studies showed that only $2 \%$ of the enamel treated surface with phosphoric acid $\left(\mathrm{H}_{3} \mathrm{PO}_{4}\right)$ was ideally etched [11,12]. This acid resistance can be caused by the external layer of organic substances which prevents the acid to reach the enamel mineral phase and reduce the quality of etching [13]. To deal with this problem, Justus was the first one who proposed enamel deproteinization, he used $5.25 \%$ sodium hypochlorite (Na$\mathrm{OCl})$ to remove the organic matter before etching [14]. Recently, a 
proteolytic cysteine enzyme called Papain, which is extracted from the latex of the papaya, showed a great effect of dissolving proteins on the enamel surface and increased the shear bond strength of brackets [4,15-17]. Another enzyme belonging to the protease group whose proprieties are similar to those of Papain is called Ficin [18], it is extracted from the latex of the fig (Ficus carica) [19]. Therefore, the aim of our study was to test the effect of enamel deproteinization using Ficin on shear bond strength of orthodontic brackets.

\section{Materials and Methods}

Ficin was extracted from fresh fig latex in the molecular biology laboratory of the dental faculty of Monastir [20] (Figure 1). Light bond orthodontic adhesive from Reliance Orthodontics USA and GAC $^{\text {TM }}$ Thin Arch mini brackets were used in this study.

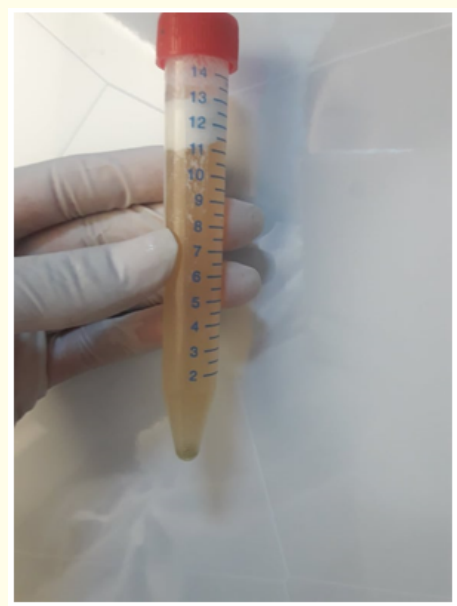

Figure 1: Ficin extracted from fresh fig latex.

Teeth (incisors, canines and premolars) were cleaned and stored in water; the enamel surface of the selected teeth was free of any abnormality. 42 teeth were selected and divided randomly into two groups. The overall retention surfaces were equal in both groups.

\section{Group 1: Control group}

The enamel surface has been etched with orthophosphoric acid for 30 seconds, washed with water and air dried. The bonding of the brackets was done according to the manufacturer's instruc- tions, a thin layer of sealant was spread on the etched enamel and the paste was applied in the bracket base. Photopolymerization has been applied for 30 seconds using a LED appliance (Stardent, China-1200 1500MW/ $\mathrm{cm}^{2}$ ).

\section{Group 2: Test group}

The enamel surface has been treated with ficin for 30 seconds, washed with water and air dried. Then, the same protocol of the control group was applied.

All the brackets were double ligated using a $0.3 \mathrm{~mm}$ orthodontic ligature wire (Figure 2) and have been stored in saline solution at room temperature for 24 hours. The shear bond strength was measured in the department of mechanical engineering of the national engineering school of Monastir using Lloyd-Ametek EZ20 Material Testing Machine. The cross-head speed was adjusted at $2 \mathrm{~mm} /$ minute and the traction was applied parallel to the tooth surface to simulate shear force (Figure 3).

The data, obtained in Newton, was converted to Mega Pascal MPa then statistically analysed using SPSS version 22 software. Independent-samples Student's t-test was used to compare the values of the two groups with a level of confidence set at $95 \%$ and a significance level equal to 0.05 .

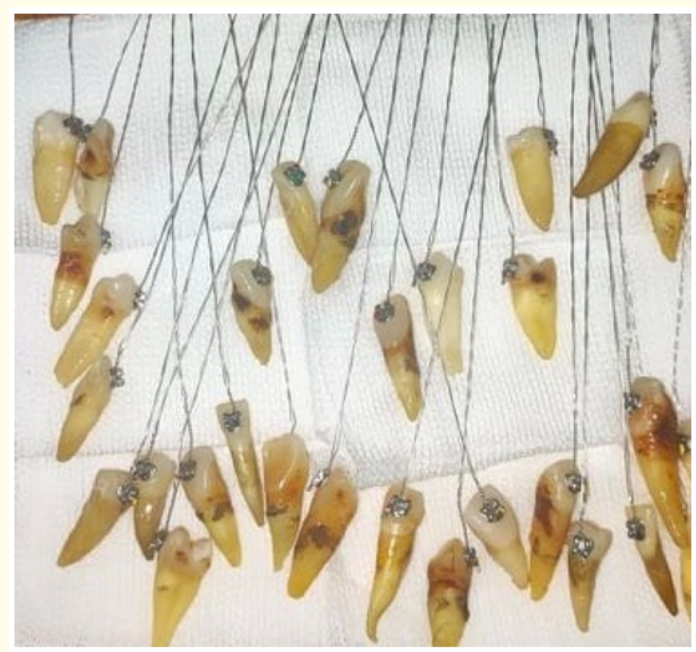

Figure 2: Preparing teeth for the mechanical test. 


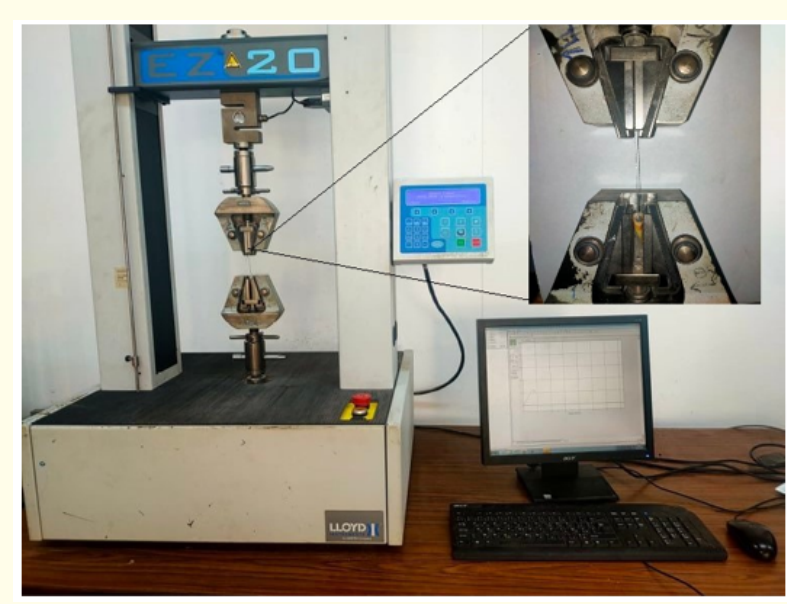

Figure 3: Shear bond strength measuring.

\section{Results}

The mean shear bond strength in control group was $7.7 \mathrm{MPa}$ with a standard deviation equal to $2.83 \mathrm{MPa}$. However, the test group showed higher figures, the mean shear bond strength was 9.22 MPa with 3.51 MPa as a standard deviation.

The mean shear bond strength was increased by $19.74 \%$ after deproteinising the enamel surface with ficin. According to Student $t$-test, the difference of shear bond strength between the two groups was statistically significant $(\mathrm{p}=0.037)$ (Table 1$)$.

In both groups, maxillary central incisor brackets showed the lowest shear bond strength, whilst, mandibular incisor brackets presented the highest figures.

\begin{tabular}{|c|c|c|c|c|c|c|}
\hline Groups & $\mathbf{N}$ & $\begin{array}{l}\text { Minimum } \\
\text { (MPa) }\end{array}$ & $\begin{array}{l}\text { Maximum } \\
\text { (MPa) }\end{array}$ & $\begin{array}{l}\text { Mean } \\
\text { (MPa) }\end{array}$ & $\begin{array}{c}\text { Standard Deviation } \\
\text { (MPa) }\end{array}$ & $\mathbf{p}^{*}$ \\
\hline Control & 21 & 3.46 & 13.76 & 7.7 & 2.83 & \multirow{2}{*}{0.037} \\
\hline Test & 21 & 5.12 & 14.94 & 9.22 & 3.51 & \\
\hline
\end{tabular}

Table 1: Groups, Minimum, Maximum, Mean, Standard deviation of the shear bond strength values and Statistical comparison of the two groups.

* Student's t-test.

\section{Discussion}

Tooth surface is normally covered with the acquired pellicle which contains mainly proteins [21]. This organic membrane protects enamel from acid used for etching and consequently reduces the quality of bonding [11,12]. In order to overcome this issue, Justus proposed to use sodium hypochlorite to deproteinise enamel surface before etching it with phosphoric acid [14]. Sodium hypochlorite is not the only molecule with deproteinization proprieties, there are many other chemicals and natural substances that can dissolve proteins such as ficin.

Ficin is classified as a sulfhydryl protease isolated from the latex of fig trees [22]. It is traditionally used to tenderise meat and to clot milk, however, it has also modern uses such as the production of bioactive peptides and fragments of antibodies [19].
The aim of our study was to assess shear bond strength of orthodontic brackets after using ficin as a deproteinizing agent before applying orthophosphoric acid. Ficin used in the present study was extracted from fresh fig latex and applied in raw state.

Results showed that the group with a deproteinization step presented a higher shear bond strength compared to the group with classical bonding protocol. The difference was statistically significant $(\mathrm{p}=0.037)$.

Ficin has not been used for enamel deproteinization before, however, other substances were tested. In fact, using a $5.25 \%$ sodium hypochlorite $(\mathrm{NaOCl})$ solution was the first tried method to dissolve the organic layer [14]. While some studies confirmed the deproteinising effect of sodium hypochlorite [4,23], others didn't find significant results $[16,24]$. Both concentration and application 
time influenced the efficiency of sodium hypochlorite to remove the organic layer and improve bonding [16,25]. Espinosa., et al. showed that the conditioning of enamel surface and the quality of the etching pattern were improved after using $5.25 \% \mathrm{NaOCl}$ for 1 minute as a deproteinization step before etching with orthophosphoric acid [25].

Papain, an enzyme extracted from papaya latex, is another deproteinising substance used to enhance orthodontic brackets retention. Indeed, in a study conducted by Pithon., et al. it was demonstrated that a $10 \%$ papain gel increases the shear bond strength of brackets bonded either with composite resin or a resin-modified glass ionomer cement [16]. Moreover, not only shear bond strength was increased but also tensile bond strength was improved by treating the enamel surface with papain [15].

More studies are needed to check the effect of enamel deproteinization using ficin on tensile bond strength and to find the optimal concentration and application time of this enzyme.

\section{Conclusion}

The deproteinization of enamel surface using ficin improved the shear bond strength. Thus, it is recommended to add a deproteinization step to the classical bonding protocol to increase orthodontic brackets retention.

\section{Bibliography}

1. Beckwith FR., et al. "An evaluation of factors affecting duration of orthodontic treatment". American Journal of Orthodontics and Dentofacial Orthopedics 115.4 (1999): 439-447.

2. Skidmore KJ., et al. "Factors influencing treatment time in orthodontic patients". American Journal of Orthodontics and Dentofacial Orthopedics 129.2 (2006): 230-238.

3. Popowich K., et al. "Predictors for Class II treatment duration". American Journal of Orthodontics and Dentofacial Orthopedics 127.3 (2005): 293-300.

4. Panchal S., et al. "Effects of different deproteinizing agents on topographic features of enamel and shear bond strength - An in vitro study". Journal of Orthodontic Science 8.1 (2019): 17.

5. Stasinopoulos D., et al. "Failure patterns of different bracket systems and their influence on treatment duration: A retrospective cohort study". Angle Orthodontist 88.3 (2018): 338347.
6. Pizzo G., et al. "Root resorption and orthodontic treatment. Review of the literature". Minerva Stomatology 56.1-2 (2007): 31-44.

7. Knobloch LA., et al. "Microleakage and bond strength of sealant to primary enamel comparing air abrasion and acid etch techniques". Pediatric Dentistry 27.6 (2005): 463-469.

8. Martínez-Insua A., et al. "Differences in bonding to acid-etched or Er:YAG-laser-treated enamel and dentin surfaces". Journal of Prosthetic Dentistry 84.3 (2000): 280-288.

9. Shah J and Chadwick S. "Comparison of 1-stage orthodontic bonding systems and 2-stage bonding systems: a review of the literature and the results of a randomized clinical trial". Orthodontie Française 80.2 (2009): 167-178.

10. Coreil MN., et al. "Shear bond strength of four orthodontic bonding systems". American Journal of Orthodontics and Dentofacial Orthopedics 97.2 (1990): 126-129.

11. Hobson RS., et al. "A quantitative study of enamel acid etch patterns on surfaces used for retention of resin-bonded fixed prostheses". European Journal of Prosthodontics and Restorative Dentistry 13.3 (2005): 123-128.

12. Hobson RS., et al. "Acid-etch patterns on the buccal surface of human permanent teeth". Archives of Oral Biology 47.5 (2002): 407-412.

13. Hilton TJ., et al. "Summitt's Fundamentals of Operative Dentistry: A Contemporary Approach". Quintessence Publishing Company Incorporated (2013).

14. Justus R., et al. "A New Technique With Sodium Hypochlorite to Increase Bracket Shear Bond Strength of Fluoride-releasing Resin-modified Glass Ionomer Cements: Comparing Shear Bond Strength of Two Adhesive Systems With Enamel Surface Deproteinization Before Etching". Seminars in Orthodontics 16.1 (2010): 66-75.

15. Rosyida NF., et al. "Improving Tensile Bond Strength of Orthodontic Bracket by Applying Papain Gel as an Email Deproteinization Agent". Journal of Dentistry Indonesia 24.3 (2017): 70-74.

16. Pithon MM., et al. "Effect of $10 \%$ papain gel on enamel deproteinization before bonding procedure". The Angle Orthodontist 82.3 (2012): 541-545. 
17. Agarwal R., et al. "Enamel Deproteinization using Papacarie and $10 \%$ Papain Gel on Shear Bond Strength of Orthodontic Brackets Before and After Acid Etching". Journal of Clinical Pediatric Dentistry 39.4 (2015): 348-357.

18. Milošević J., et al. "Comparative stability of ficin and papain in acidic conditions and the presence of ethanol". Amino Acids 51.5 (2019): 829-838.

19. Morellon-Sterling R., et al. "Ficin: A protease extract with relevance in biotechnology and biocatalysis". International Journal of Biological Macromolecules 162 (2020): 394-404.

20. Di Pierro G., et al. "Antioxidant activity of bovine casein hydrolysates produced by Ficus carica L.-derived proteinase". Food Chemistry 156 (2014): 305-311.

21. Hannig C., et al. "Enzymes in the acquired enamel pellicle". European Journal of Oral Sciences 113.1 (2005): 2-13.

22. Yang Y., et al. "Intrinsic Peroxidase-like Activity of Ficin”. Scientific Reports 7 (2017): 43141.

23. Mohammadi N., et al. "The effect of sodium hypochlorite enamel pretreatment on the shear bond strength of fissure sealant using a resin-modified glass ionomer cement and a fluoride-releasing self-etch resin adhesive". Dental Research Journal (Isfahan) 18 (2021): 13.

24. Harleen N., et al. "Enamel deproteinization before acid etching and its effect on the shear bond strength--an in vitro study". Journal of Clinical Pediatric Dentistry 36.1 (2011): 19-23.

25. Espinosa R., et al. "Enamel deproteinization and its effect on acid etching: an in vitro study". Journal of Clinical Pediatric Dentistry 33.1 (2008): 13-19.

\section{Assets from publication with us}

- Prompt Acknowledgement after receiving the article

- Thorough Double blinded peer review

- Rapid Publication

- Issue of Publication Certificate

- High visibility of your Published work

Website: www.actascientific.com/

Submit Article: www.actascientific.com/submission.php

Email us: editor@actascientific.com

Contact us: +919182824667 